\title{
CÓDIGO DE DIREITO CANÔNICO: A ERA FRANCISCO E SUAS MUDANÇAS NOS PROCESSOS DE NULIDADE MATRIMONIAL
}

\section{ARTIGO ORIGINAL}

SILVA, José Antonio da ${ }^{1}$

SILVA, José Antonio da. Código de Direito Canônico: a era Francisco e suas mudanças nos processos de nulidade matrimonial. Revista Científica Multidisciplinar Núcleo do Conhecimento. Ano 04, Ed. 06, Vol. 12, pp. 149-163. Junho de 2019. ISSN: 2448-0959

\section{RESUMO}

O presente trabalho visa abordar o tema do Direito Canônico e sua evolução até os dias atuais. Desde sua origem, o Direito Canônico influenciou e foi influenciado pela sociedade na qual estava contido. As condutas da igreja e sua relação direta com a comunidade atendida por essa foram sempre norteadas por códigos e determinações eclesiásticas. O trabalho, por meio de um levantamento bibliográfico e releitura de artigos e doutrinas busca apresentar uma melhor explanação do assunto, com uma síntese dos principais pontos de interesse acadêmico. O principal objetivo do trabalho é delimitar a origem e evolução do direito e normas da igreja. Nas últimas décadas, pode-se perceber um movimento para que haja a reaproximação da igreja com seu rebanho e, em especial, neste momento de regência do Papa Francisco, é possível notar pontos notáveis de mudança de conduta que, motivada por uma busca de igualdade social e compaixão, apresenta notórias transformações, sejam em pontos

\footnotetext{
${ }^{1}$ Bacharel e Teologia, pelo Centro de Ensino Superior de Juiz de Fora/MG-CES/JF. Licenciado em Filosofia pela Faculdade Católica de Anápolis. Especializado em Bioética, Docência do Ensino Superior, Ensino Religioso, Docência de Filosofia e Sociologia. Mestre em Direito Canônico e Doutorando em Direito Canônico pela Pontifícia Universidade Católica de Buenos Aires/Argentina.
} 
administrativos ou que versem diretamente sobre a vida das pessoas, como é o caso do matrimônio católico.

Palavras-chave: Direito, canônico, igreja, conduta, matrimônio católico.

\section{INTRODUÇÃO}

A formação do Direito, como hoje o conhecemos, com suas peculiaridades e estruturas basilares, passou ao longo dos séculos por grandes transformações. Tais mudanças deram-se em especial pela evolução social dos indivíduos e anseios da sociedade de cada época.

Ao falar de construção histórica e social, a Igreja será sempre lembrada como estrutura de suma importância, sendo inclusive a responsável por grande parte do período de governo direto na Idade Média. Porém, como norteadora de costumes e tradições, com o intuito de guiar a sociedade por caminhos preparados por seus ensinamentos cristãos, a mesma também necessita de normas e regimentos internos para sua composição como organismo vivo, de capacidade organizacional e de interferência no contexto jurídico daqueles que a representam ou participam.

Na seara de necessidade de normas regulatórias nasce o chamado Direito Canônico, uma unidade de normas jurídicas, nascidas e com aprovação de autoridade eclesiástica competente e cuja finalidade é a regulamentação de matérias de competência da Igreja. É tal ramo do Direito, verdadeiramente um ordenamento jurídico autônomo, o mais antigo, cultivado e debatido depois do Direito Romano, sabida base de todos os outros. Possui características próprias, como a exclusividade atribuída aos fiéis da Igreja Católica, ou seja, só os católicos são sujeitos de direitos e de deveres consagrados no Direito Canônico.

Segundo nos ensina Bacelar, em suas palavras, costuma-se designar por Direito Canônico o conjunto de normas jurídicas oriundas da Revelação ou emanadas pela autoridade da Igreja Católica, que têm por objetivo a disciplina do governo da Igreja e da relação dela com seus fiéis, bem como da relação dos fiéis entre si. O autor ainda 
explica que o qualificativo "canônico" tem origem na palavra latina cânon, recebida do grego kánon (guia, norma de medida), referindo-se a toda prescrição ou diretriz emanada da autoridade eclesial (RENAN VICTOR BOY BACELAR, 2018).

Neste trabalho foi realizada uma leitura e pesquisa baseadas em ensinamentos referentes ao tema, com um levantamento bibliográfico da matéria, em busca de informações que possam aclarar o tema. Ante a riqueza de material histórico, foi possível apresentar no primeiro contexto a descrição da origem e evolução do Direito Canônico, com passagens históricas pontuais.

Num segundo momento, aborda-se as principais mudanças na legislação da Igreja, através do pontífice do Papa Francisco e, como tema principal do último tópico, foi explorada a questão da nova postura em relação aos matrimônios e dissolução na Igreja Católica. Conhecer o embasamento do Direito Canônico e sua transformação ao longo de sua aplicação e desenvolvimento da própria Igreja, proporciona ao leitor uma compreensão de seu sentido e necessidade de existência.

\section{DIREITO CANÔNICO: ORIGEM E EVOLUÇÃO}

O que se tem de conhecimento acerca do Direito Canônico, com suas determinadas estruturas e legislações, foi moldado por uma evolução social ao longo dos séculos, na qual também influenciou o Direito e o Estado. A Igreja nada mais é do que um grupo social organizado que demanda por regras e normas em sua constituição.

Por meio das palavras de Miranda citado por Steffen, podemos entender que, como uma estrutura social e visível, são necessárias normas a fim de se tornar visível sua estrutura hierárquica e orgânica; também, para que se organize de forma devida o exercício das funções, principalmente no que se refere o poder sagrado e da administração dos sacramentos. A fim de, por igual, que se estruturem conforme a justiça (diferentemente da justiça laica), as relações interpessoais entre fiéis, embasadas na caridade, de forma a garantir os direitos de cada um. Por fim, com o propósito de as iniciativas comuns empreendidas em benefício de uma vida regida 
pelos ensinamentos cristãos. Todas elas apoiadas e com garantia de cumprimento pelas leis canônicas. (STEFFEN, CARLOS JOSÉ MONTEIRO).

Para melhor elucidar o assunto, devemos conceitua-lo segundo a doutrina. De acordo com Tarcísio Pedro Vieira, em seus estudos que abordam diretamente autores que circundam de forma profunda o código de direito canônico, apresenta que é certo dizer que o direito canônico, "etimologicamente, vem do grego kanon, significa régua de medir, regra, no sentido de esquadro para traçar linhas que se unem em ângulo reto, guia, norma, princípio, determinação emitida pela autoridade legítima, equivalente à lei".

Por meio do desenvolvimento da sociedade, em especial na Idade Média, entendemos a necessidade de regular as relações entre os fiéis que passaram a se submeter aos ensinamentos da doutrina cristã. Esse processo motivou o surgimento dos primeiros esboços de um ordenamento jurídico canônico, cujas bases foram extraídas do Evangelho e da tradição oral, o que deu origem a um Direito paralelo ao romano, segundo nos ensina Hilário Franco Junior.

Os cristãos sempre foram numerosos, e se multiplicavam na Idade Média. Foi, no entanto, na sua concepção junto mesmo ao próprio Cristianismo que se encontrou a necessidade de tribunais separados para versarem sobre seus dilemas. Conforme explica John Gilissen sobre a origem da competência dos Tribunais Eclesiásticos, estes tinham como responsabilidade a jurisdição da Igreja, com representação feita pelo Bispo, perante os quais se submetiam os cristãos.

As questões envolvendo cristãos se avolumavam significativamente, na mesma medida em que o cristianismo se disseminava pela Europa Ocidental; logo, a necessidade de regulamentação de um processo que assegurasse a justiça divina mostrava-se iminente. As primeiras regras foram extraídas de julgamentos perante os tribunais de conciliação, cuja síntese seria utilizada para esclarecer questões futuras, em situações análogas. Isto é, em referência a regulamentação por meio da tradição oral. 
Aqueles que detinham o poder de julgar passavam a extrair de cada julgamento uma regra sintética que pudesse iluminar futuras decisões em hipóteses semelhantes. Esse estrato receberia o nome de cânone (do grego Kanoon, significado regra), daí o direito canônico. (Tucci e Azevedo, 2001, p. 19).

Inegavelmente, o Direito Canônico teve sua ascensão por volta de meados do século III. No ocidente europeu, o Imperador Constantino (ano 313) foi, sem dúvida, o precursor da saída da Igreja Católica do "subterrâneo" para se tornar, inicialmente, uma Instituição do Estado e tal supremacia perdurou por muitos séculos. O declínio da incidência do Direito Canônico somente ocorre na Idade Moderna, a partir do século XVI.

Várias razões contribuíram para esse declínio. Entre elas, a divisão da Igreja Católica provocada pela Reforma Protestante, que ocasionou em uma separação e perda de fieis, sem que, com isso, a Igreja perdesse seu poder. O número de seguidores continuou significativo, bem como sua importância política, financeira e social. Contudo, após a Revolução Francesa, houve uma separação entre Estado e Igreja.

No Brasil, a separação entre Estado e Igreja é recente, ao se levar em consideração a evolução legislativa oficial do Estado Brasileiro. Somente com a proclamação da República em 15 de novembro de 1889, e a promulgação da Constituição da República em 1891, o Estado e a Igreja são separados. Apesar de o catolicismo se constituir como religião oficial do Estado, é permitida a existência de outras igrejas, bem como a liberdade de culto.

Como exemplo, temos a obrigatoriedade do casamento civil, prevista no artigo 72 , $\S 4.0$, da Constituição da República, anteriormente apenas celebrado em rituais religiosos, foi finalmente oficializada. Esse processo eliminou definitivamente uma das únicas atribuições dissidentes da Idade Medieval, que mantinha o vínculo entre as duas instituições - Estado e Igreja. Mesmo separados, a legislação canônica ainda é vista com suma importância. 
Sobre isso nos ensina Gilissen, ao versar sobre o assunto. Nas palavras do autor:

O Direito canônico é ainda um direito bem vivo. Apesar da secularização das instituições públicas e privadas e da separação da Igreja do Estado estabelecidas em diversos países, o direito canônico continua a reger as relações entre os membros da comunidade cristã, uma vez que estes se Ihe submetem voluntariamente [...] (Gilissen, 1995, p. 135).

Com séculos de evolução e por diferentes papados passados, o atual código, datado do ano de 1983 é o que se encontra em vigor. O direito canônico atual é composto por dois documentos: Codex luris Canonici $(\mathrm{CIC})$ que, em português, traduz-se por código de direito canônico; o Codex Canonum Ecclesiarum Orientalium(CCEO) ou Código dos Cânones das Igrejas Orientais (referente às Igrejas em comunhão como papa, mas de outro rito, como por exemplo a Igreja Católica Maronita, entre outras).

Para regular as relações entre os Estados e a Santa Sé, no respeito não só pela liberdade religiosa mas também pelas tradições e cultura dos povos, existe o direito internacional corporizado em Concordatas, Acordos, Tratados ou Concórdias. Nas palavras de Lima, citado por Lombardi, o Direito Canônico é, portanto, a lei da Igreja Católica, um conjunto das regras regulamentadoras da vida na comunidade eclesial, cuja relação está no cotidiano dos católicos de todo o mundo. Essas normas se originaram no Império Romano e segue até a contemporaneidade, mas é baseada na herança jurídica e legislativada Revelação e da Tradição.

O Direito Canônico é a organização jurídica que se caracteriza pela conjunção de regras, cuja autoridade compete à Igreja Católica, que a determina ou faz valer. Tem vários várias ramificações, como por exemplo o Direito Administrativo Canónico, o Direito Patrimonial Canônico e o Direito Penal Canônico, de entre outros. No Código de Direito Canônico, encontram-se organizadas quer sejam normas materiais, quer sejam normas processuais.

Por meio da Carta Apostólica em forma de Motu Proprio Omnium in Mentem, datada do dia 26 do mês de outubro do ano de 2009, com pareceres dos Padres da 
Congregação para a Doutrina da Fé e do Pontifício Conselho para os Textos Legislativos, como também das Conferências Episcopais, foram modificadas algumas normas do direito canônico. Estas, designadamente, são os cânones 1008, 1009, 1086, 1117 e 1124 do Código de Direito Canônico, que trata acerca da aprovação e definição dos requisitos necessários para a validade dos sacramentos da ordem e do matrimónio e sobre o ato formal da separação da Igreja.

Caso novas mudanças ocorram na sociedade humana e isso exija nova revisão do Código, a Igreja é permitida de tomar o caminho da renovação, tal como é registrada na história as adaptações feitas pela Instituição às novas circunstâncias de forma adequada. Como reconhecia o Papa João XXIII, "o mundo tem os seus problemas e a Igreja sempre tomou a peito esses problemas. A doutrina da Igreja abarca o homem todo, no seu corpo e na sua alma, e pede-nos que sejamos, na terra, peregrinos a caminho da pátria celeste".

Com o intuito de se adequar às novas demandas sociais, o código canônico tem recebido aportes dos últimos Papas, como forma de se modernizar em seu contexto, seja como instituição ou ainda em relação aos seus fiéis.

\section{O DIREITO CANÔNICO MODERNO}

O Direito da igreja Católica, conhecido como Direito Canônico, está contido nos decretos compilados pelo canonista e teólogo Graciano ("Concordia discordantium Canonum"), Nos "Decretali" de Gregório IX, no "Liber Sextus" de Bonifácio VII e no "Liiber Septimus Decretalium" de João XXII.

Toda essa legislação foi enfeixada numa única compilação, denominada de "Corpus luris Canonici", pelo Concilio de Basiléia (1431-1443), e se manifesta por meio de determinadas legislações, como é o caso do Código de Direito Canônico (1983) e Código dos Cânones das Igrejas Orientais (1990), tal como pelo Papa João Paulo II, assim como os Acordos Internacionais, dentre os quais se destaca o "Acordo Brasil Santa-Sé", representado pelo decreto federal 7.107/10. 
Tal Código, em sua 4⿳亠 Edição, de rubrica do Papa João Paulo II, resguarda ainda em sua exposição introdutória de motivos, que

"...de modo algum tem o objetivo de substituir a fé, a graça, os carismas e principalmente a caridade na vida da Igreja ou dos fiéis. Pelo contrário, o seu fim é antes o de criar tal ordem na sociedade eclesial que, atribuindo a primazia ao amor, à graça e aos carismas, torne ao mesmo tempo mais fácil o seu desenvolvimento ordenado na vida quer da sociedade eclesial, quer também de cada um dos homens que dela fazem parte. O Código, como principal documento legislativo da Igreja, baseado na herança jurídica e legislativa da Revelação e da Tradição, deve considerar-se o instrumento indispensável para assegurar a ordem tanto na vida individual e social, como na própria atividade da Igreja. Por isso, além de conter os elementos fundamentais da estrutura hierárquica e orgânica da Igreja, estabelecidos pelo seu Divino Fundador ou baseados na tradição apostólica ou na mais antiga tradição, e ainda as principais normas referentes ao exercício do tríplice múnus confiado à própria".( JOĀO PAULO II)

O Papa Bento XVI se justifica de forma oportuna que, no discurso anual dirigido ao Pontifício Conselho para os Textos Legislativos, sobre a importância da divulgação e do cumprimento do Direito Canônico:

Antes de tudo, a lei da Igreja é lex libertatis: lei que nos torna livres para aderir a Jesus. Por isso, é necessário saber apresentar ao Povo de Deus, às novas gerações e a quantos são chamados a fazer com que seja respeitada a norma canônica, o vínculo concreto que ela tem com a vida da Igreja, para a salvaguarda dos delicados interesses das realidades de Deus, daqueles que não dispõem de outras forças para se fazer valer, mas também em defesa daqueles delicados "bens" que cada fiel recebeu gratuitamente em primeiro lugar o dom da fé, da graça de Deus que na Igreja não podem permanecer desprovidos de uma adequada tutela da parte do Direito. (BENTO XVI). 
De acordo com a revista cristā, Veritatis Splendor, esses são alguns dos pontos principais destinados a influir de maneira inovadora nas futuras modificações da Igreja como organismo vivo, por meio da nova consciência eclesial, igualdade entre os fiéis, visão harmônica dos princípios constitucionais, o empenho pela unidade dos cristãos, a abertura a todas as religiões e todos os homens, a adesão pessoal ao catolicismo e a visão da igreja em constante estado de missão.

Com base nesse estudo, é possível entender-se que a Igreja busca pela modernização de seu segmento, sem que, com isso, perca suas raízes históricas. Mas como toda organização, necessita se adequar aos anseios da sociedade na qual está contextualizada.

O autor Pedro Lombardia, em seu livro Lições de Direito Canônico, explora bem o assunto sobre o tema e suas tentativas de adequação. $O$ autor, por meio de de resenha de Alexandre Silva, nos mostra que mostra que "a tradição canônica com a introdução de técnicas modernas contribuiu para uma formalização mais elaborada do ordenamento jurídico" (p. 191), uma vez que se trata de uma ordenação da razão, cuja visão se volta ao bem comum, difundido por um responsável de cargo eclesiástico, e complementa com referência "à racionalidade entendida como coerência entre direito divino e direito humano" (p. 192).

Com essa análise, o mesmo autor ensina sobre elementos essenciais no entendimento do Novo Código de 1983, cujos apontamentos direcionam a um novo caminho a ser percorrido pela Igreja Católica. O novo Código está de acordo com o Concílio Vaticano II e, por isso, se acorda também com as novas demandas do mundo atual.

Mudanças ocorreram nas últimas décadas, desde o pontífice do Papa João Paulo II. No entanto, foi a partir do ano 2013, com a chegada do Papa Francisco, que uma nova releitura da igreja começou a ser apresentada à sociedade atual 


\subsection{PRINCIPAIS MUDANÇAS DA IGREJA NA ERA FRANCISCO}

Ao assumir o mais alto posto da Igreja Católica, no ano de 2013, o Papa Francisco trouxe consigo ideias de revolucionar alguns estatutos da Igreja. Como primeiro representante latino do Vaticano, Francisco, que tem como nome original Jorge Mario Bergoglio, após a renúncia de Bento XVI, ficou conhecido por sua especial atenção às novas gerações e condutas sociais.

Um de seus primeiros atos como Papa, foi se pronunciar e garantir apoio e proteção à jovens reunidos no Rio de Janeiro, que participavam das jornadas mundiais da Juventude, em julho de 2013. Sempre em busca de uma reaproximação com seus devotos e com a sociedade em geral por meio de suas mudanças importantes na igreja, que refletiram muito de sua conduta pessoal. A aproximação com outras religiões e outros povos em suas viagens, bem como a imposição de um novo posicionamento dos membros efetivos da Igreja, como padres e bispos, podem ser avaliadas em normas efetivadas por Francisco.

Em 1 de setembro de 2015 , o Papa surpreende o mundo ao pedir que os sacerdotes de todo o mundo concedam perdão às mulheres que praticaram aborto. No mesmo ano, visita Fidel Castro e Barack Obama. A atenção dedicada do Papa à mulher, família e classes antes menos priorizadas pela Igreja também são latentes. Neste contexto passou a entregar cargos às mulheres de importância, dentro da estrutura da igreja, e também falar com pessoas de diversas orientações sexuais, em seus famosos discursos.

O Papa também assumiu posturas rígidas diante de denúncias de abusos por parte de padres e membros do clero, criando uma comissão para apurar todas as denúncias de forma efetiva. Criou também uma reforma interna, em busca de organizar as finanças do Vaticano.

Todas essas transformações fizeram do Papado de Francisco um desafio sobre inclusão e renovação. Porém, sua resolução acerca do instituto do casamento e sua possível declaração de ato nulo foi a que causou maior impacto direto na vida dos 
cristãos e fieis da igreja, especialmente pelo fato de influenciar diretamente na vida civil e social dos mesmos, já previsto no Código de Direito Canônico, o Papa faz uma reforma na dinâmica do processo.

\section{O MATRIMÔNIO E O PROCESSO DE NULIDADE NA NOVA FASE DA IGREJA}

Acredita-se que, depois do batismo, que é o ato inicial pelo qual uma pessoa ingressa formalmente no corpo da Igreja, o casamento religioso pode ser considerado como a principal matéria de desempenho da mesma. A história do casamento caminha junto às fases de civilização e sua evolução como sociedade. Nas palavras de Abílio Soares de Vasconcelos (2007, p.4) entende-se que, para a comunidade romana, o casamento se configurava como um ato de caráter reservado e contratual, desprovido de qualquer tipo de formalidade, não sendo exigida sequer a coabitação.

$\mathrm{Na}$ Idade Média, a Igreja, com sua força de Estado, passa a legislar sobre o casamento. Conforme nos ensina Eduardo de Oliveira Leite (1991, p. 149) referente à herança do Concílio de Niceia na intervenção do imperador Constantino, favorável à Igreja, transforma-a num poder espiritual tão forte quanto o Império. Desde sua primeira intervenção no ato do matrimônio, pode-se perceber uma evolução decorrente do próprio desenvolvimento da sociedade, porém, sem nunca perder a importância e força de suas resoluções.

No entanto, o que estava diretamente ligado como forma civil e religiosa, foi separado em meados do século XVIII, com a Revolução Francesa que altera a estrutura tradicional da família, retira-lhe todo caráter religioso e a submete a um regime de caráter e igualitário. (LEITE, 1991, p. 371). Desta forma, encontra-se agora uma força mais preponderante em relação aos laços civis.

Separado da religiosidade e agora nominado como contrato civil entre homens e mulheres, o ato do casamento perde o controle total da Igreja, ao mesmo passo que é levado por seus interesses particulares. Agora, o casamento, conforme nos ensina a professora Maria Helena Diniz, é o vínculo jurídico de auxílio mútuo (material e 
espiritual) entre o homem e a mulher, em que há uma integração fisiopsíquica e a constituição de uma família. (DINIZ, 2011, p. 51).

Ainda encontra sua definição nas palavras do douto Clóvis Beviláqua, em uma afirmação de que o casamento é um contrato de reciprocidade mútua, pelo qual um casal (homem e mulher) será unido de forma indissolúvel e terá suas relações sexuais legitimadas, o que estabelece a mais estreita comunhão de vida e interesses, num compromisso com a criação e educação da prole que está para nascer.

$\mathrm{Na}$ ordem jurídica da Igreja, o casamento também possui sua definição. Descreve Abílio Soares de Vasconcelos (2007, p.22) sobre a definição de casamento na Lei Ordinária Eclesiástica - Cân. 1055, §10, 20:

"O pacto matrimonial, pelo qual o homem e mulher constituem entre si e para sempre um consórcio de vidas, ordena-se, por sua índole natural, ao bem dos cônjuges na vida em comum e à geração e educação dos filhos;Entre pessoas batizadas validamente não há pacto matrimonial válido que não seja Sacramento (Basta que um dos contraentes não seja batizado para que o casamento não possa ser elevado a sacramento)".

O casamento dentro do Direito Moderno passa a ter uma natureza contratual. E tal concepção, segundo ensina Lessi, citando Diniz, o matrimônio é um contrato civil, cuja regência se dá por regras comuns a quaisquer contratos, com consentimento dos envolvidos. Feito de forma recíproca e manifestada por sinais exteriores. (DINIZ, 2011, p. 54).

E como tal, o contrato possui direitos e obrigações que devem ser respeitados. Juntamente com o Poder do Estado em celebrar o casamento, enquanto ato civil, também deu continuidade a Igreja com poderes para a realização e validação do mesmo. O principal documento jurídico do Brasil, sua Constituição Federal de 1988, seguindo suas antecessoras, versa sobre a matéria do casamento civil e religioso. A CF de 1988, no art. 226, §10, estatui que o casamento é civil e gratuita a celebração e , no $\S 2^{\circ}$, acresce que o religioso tem peso civil dentro dos termos da lei. O casamento 
religioso (a fim de efeitos civis) está colocado nos arts. 1.515 do Código Civil. (DINIZ, 2011, p. 67), citados por Lessi.

Na mesma esteira, assim como sua validação, a lei civil também trata de sua nulidade em diversos casos, bem como o pedido de divorcio, que devem sempre ocorrer através de decisão judicial, com o intuito de respeitar os rigores da lei ou ainda a vontade das partes envolvidas, quando capazes.

$\mathrm{Na}$ visão da igreja casamento é definido pela como sacramento, instituído por Jesus Cristo e regido pelos princípios da unidade e da indissolubilidade, tornando-se consórcio vitalício para os cônjuges. Com base nesse conceito, a Igreja Católica não permite a dissolução da união firmada perante Deus e consumada; contudo, pode declarar sua inexistência diante das hipóteses previstas no Código de Direito Canônico de 1983 (CIC), com submissão da matéria aos Tribunais Eclesiásticos.

A nulidade, definida como possível no Código Civil Brasileiro, conforme nos ensina Junqueira (2009) também é possível no âmbito do casamento religioso, mesmo através da conhecida doutrina de indissolubilidade conhecida como - Familiaris consortio, do Papa João Paulo II. Neste caso, o casamento não se dissolvera através de um divorcio, mas sim, com uma declaração de nulidade através de uma sentença advinda de uma autoridade responsável na Igreja.

Sobre os princípios da unidade e da indissolubilidade que norteiam o casamento religioso, Giorgio Feliciani (1994) especifica que a doutrina influenciou o conceito de matrimônio previsto no Código Canônico de 1983.

Efetivamente, a Constituição Gaudium et Spas (n. 48-49) adverte que 'a íntima união, enquanto doação mútua de pessoas, como também o bem dos filhos, exigem a fidelidade plena dos cônjuges e requerem a unidade indissolúvel'. E, coerentemente, o novo Código identifica as propriedades essenciais do matrimônio com a unidade $e$ a indissolubilidade que, no matrimônio cristão, encontram uma 
consciência especial, por força do sacramento. (Feliciani, 1994, p. 164, grifo do autor).

Esse era um processo que demorava anos e que se estendia por demandar a sentença de dois Tribunais. Foi considerado um dos principais desafios do Papado de Francisco que, no final do ano de 2015 introduziu — com a carta apostólica Mitis ludex Dominus lesus - um conjunto de reformas no processo de declaração da nulidade do casamento católico, tornando-o mais rápido e acessível.

Em uma carta motu proprio (por iniciativa própria), Mitis IUDEX DOMINUS IESUS e MITIS ET MISERICORS IESUS, acerca da Reforma do Processo canônico voltada às causas de declaração de nulidade do Matrimônioo no Código de Direito Canônico e no Código dos Cânones das Igrejas Orientais, o pontífice anula a necessidade de apresentação de duas setenças de duas instâncias eclesiásticas, de forma se seja colocada como decreto a nulidade de um matrimônio. O Papa Francisco emitiu nova norma, regida sob orientação de uma comissão de especialidade em direito canônico e cuja análise teve duração de um ano.

Tal decisão foi uma das mais comentadas em matéria de Direito Canônico e fez com que os pedidos triplicassem em menos de dois anos de promulgação do novo instituto. Um dos principais objetivos foi a reaproximação dos fiéis, o que facilitou novos casamentos religiosos, haja vista que, com a nulidade, os cristãos poderão casar-se outra vez na igreja.

Segundo nos explica Hortal Sanchez, a nova regulamentação facilita a vida de quem quer casar-se de novo. Ainda, na visão do Professor de Estudos Religiosos da Universidade Virginia Commonwealth (EUA), Andrew Chesnut defende que, tratar de problemas contemporâneos de cuidados da Igreja, o Papa tem a possibilidade de diminuir a perda de fiéis, principalmente no que se refere a religiões neopentecostais na América Latina. Com toques nas questões do catolicismo, o pontífice abre caminhos para o sínodo e, simultaneamente, acumula capital político. 
Tais mudanças em relação ao casamento são sem dúvida uma grande iniciativa do Papa Francisco em atualizar concepções históricas, que influenciam diretamente na vida religiosa e civil de seus fiéis, bem como construir uma nova relação entre o organismo religioso e seu rebanho.

O Papa Francisco rubricou uma reforma histórica como forma de simplificar a acelerar o processo que determina a nulidade do matrimônio. Daqui por diante, não é permitido que o processo tenha duração superior a um ano. A inovação da proposta foi apresentada em 8 de setembro, no Vaticano, feita por um grupo com integrantes de especialização em direito canônico e em teologia.

Apenas dois pontífices na história mais recente da Igreja possuem registro de terem feito uma reforma acerca de causas referentes a nulidade matrimonial: Bento XIV (1741) e Pio X (1908), conforme explanado por Dom Pio Vito, decano da Rota Romana e presidente da comissão encarregada. Foram registradas vinte uma regras (isto é, cânones) com modificações no Código de Direito Canônico e no Código dos Cânones das Igrejas Orientais.

Outro aspecto que exige destaque é a reforma centrada nos pobres e a aproximação d Igreja àqueles em sofrimento. Tudo em consonância com o Concílio Vaticano II. Dessa forma, apresentaremos os sete pontos-chave de dois documentos do Papa Francisco: Mitis ludex Dominus lesus e o Mitis et misericors lesus. Ambos são explicados por especialistas da comissão responsável por redigir os novos preceitos.

A denominada "Revolução Franciscana" acata a gratuidade requerida nos conformes das possibilidades das conferências episcopais, no que concerne o processo de nulidade. Salvo, somente, a justiça e a dignidade salarial dos funcionários dos tribunais. O pontífice procura demonstrar que a Igreja dialoga com a salvação das almas, não aos negócios.

A responsabilidade do bispo é maior e deve garantir que a ordem moral seja respeitada nos processos. Dentro da colegialidade, o bispo diocesano está unido às forças dos tribunais regionais, interdiocesanos e sinodais. Os bispos de suas 
respectivas dioceses terão os próprios tribunais e poderão determinar a presença de um juiz, obrigatoriamente, clérigo. Além disso, contarão com a ajuda dos tribunais regionais ou interdiocesanos e equipes próprias do tribunal no qual está inserido.

A reforma faz referência à declaração da nulidade do matrimônio e à sua validez. É necessário ressaltar que nulidade e anulação se divergem. Anulação é o cancelamento do que é existente, enquanto a nulidade se refere a casos nos quais não houve casamento, devido às faltas das condições de sua validez. Isto é, não existiu casamento. Não se anula o inexistente e, por isso, fala-se de nulidade.

A validade do matrimônio se dá na ausência de impedimento, o que inclui o consentimento livre dos cônjuges, acima de tudo. A doutrina se mantém indissolúvel no que concerne o casamento. A nulidade ocorre na falta de cumprimento do apontamento anterior. Neste caso, não houve validade no matrimônio por conta de impedimentos na união. Assim, os processos de nulidade serão encurtados, o que é visto como uma abertura às massas. O juiz, agora, está no papel de bispo, que contará com dois consultores e com os quais serão discutidas acerca da certeza moral a fim de validar a nulidade.

No entanto, é preciso ressaltar que não há certeza dupla. Quando há o caso de se entrar com recurso após sentença afirmativa, há o risco de haver rejeição in limine, por falta de argumentos. É comum ocorrer em caso de apelação instrumental, a fim de prejudicar a outra parte envolvida: comumente, o cônjuge não-católico já está casado no civil.

Mesmo com o grande número de pedidos de nulidade, a sociedade vê com bons olhos tal iniciativa e corresponde de forma positiva ao posicionamento do líder da igreja, que busca unir de forma caridosa e cristã àqueles que se sentiam outrora rejeitados.

\section{CONCLUSÃO}

O presente trabalho versou sobre o Direito Canônico em sua origem e suas atuais transformações. A igreja católica e suas normativas sempre tiveram um papel de 
importância, seja na constituição do Direito secular, influenciando diretamente ou ainda com interferência direta na vida civil de seus representantes e fiéis.

Através de uma revisão e releitura de artigos científicos e atualidades que já exploraram de alguma maneira o tema, acrescentando assuntos atuais, como a nulidade do casamento católico, como uma das mais importantes mudanças na legislação da Igreja na atualidade foi apresentada. Tais mudanças resultaram num processo mais rápido por parte dos representantes do clero, facilitando a vida dos interessados e possibilitando que esses tenham uma reaproximação com a Igreja e a religião.

O Papa Francisco busca em seu pontífice atualizar leis defasadas e reconstruir de certa forma algumas relações que outrora vinham se defasando com a ausência dos fiéis que se sentiam desfavorecidos. Também se pode observar uma nova postura organizacional e a abordagem de novos temas, que irá gerar com certeza novas reformulações.

A Igreja Católica de maneira alguma perdeu sua importância como organismo social. Suas instituições legislativas ainda possuem muito valor para àqueles que participam ativamente do seu contexto comunitário. O que se pode avaliar agora é que o novo pontífice busca a reintegração dessa importância, além de maior transparência, inclusão e reativação de seus valores verdadeiramente cristãos.

O Direito, como é sabido, acompanha a evolução da sociedade. O Direito Canônico, ao que parece, também passa a acompanhar.

\section{REFERÊNCIAS}

BACELLAR, Renan Victor Boy. Direito Canônico : Vivencias Históricas. Disponível em http://www.bibliotecadigital.ufmg.br/dspace/bitstream/handle/1843/BUOSAY5LA5/bacelar_direito_can_nico.pdf?sequence=1. Acesso em 08 de dezembro de 2018. 
BRASIL. Constituição (1988). Constituição Federal da República Federativa do Brasil. 34. ed. São Paulo: Saraiva, 2005.

CAVALCANTE, H. Introdução ao estudo do Código de cânones das Igrejas orientais. São Paulo: Loyola, 2009.

CIFUENTES, Rafael Llano. Novo Direito Matrimonial Canônico. Rio de Janeiro: Marques Saraiva, 1988.

DINIZ, Maria Helena. Curso de Direito Civil Brasileiro, 2001.

FELICIANI, Giorgio. As Bases do Direito da Igreja. São Paulo: Paulinas, 1994.

GILISSEN, John. Introdução Histórica ao Direito. Lisboa: Fundação Calouste Gulbenkian, 1995.

JOÃO PAULO II. Constituição Apostólica Sacrae Disciplinae Leges. Disponível em:

$<$ http://www.vatican.va/holy_father/john_paul_ii/apost_constitutions/documents/hf_jpii_apc_25011983_sacrae-disciplinae-leges_po.html>. Acesso em 07 de dezembro de 2018.

LEITE, Andrea Regina. Figueiredo, Alcio Manoel de Souza. DIREITO CANÔNICO CONTEMPORÂNEO: CELIBATO DOS SACERDOTES NA IGREJA CATÓLICA APOSTÓLICA ROMANA.

LESSI, Maria Cristina Rocha Pombo. Analise das nulidades do casamento canônico à luz do direito brasileiro : panorama atual. Disponível em http://tcconline.utp.br/wp-content/uploads/2014/02/ANALISE-DAS-NULIDADES-DOCASAMENTO-CANONICO-A-LUZ-DO-DIREITO-BRASILEIRO-PANARAMAATUAL.pdf. Acesso em 05 de dezembro de 2018.

LIMA, M. C. de. Introdução à história do direito canônico. São Paulo: Loyola, 1999. 
LOMBARDÍA, Pedro. Lições de direito canônico: Introdução direito constitucional parte geral. São Paulo: Loyola, 2008. 218 p.

MONTEIRO, Washington de Barros. Curso de Direito Civil. Direito de Família. São Paulo: Saraiva, 1997. v. II.

PAPA FRANCISCO. Mitis ludex Dominus lesus E Mitis Et Misericorcors lesus. Carta Apostólica do Papa Francisco em forma de Motu Próprio. Edições. CNBB.2015.

SAMPEL, Edson Luiz. Questões de direito canônico. Ed. Paulinas, São Paulo, 2010, $124 \mathrm{p}$.

STEFFEN, Carlos Jose Monteiro. Igreja e Direito Canônico. Disponível em http://tede2.pucrs.br/tede2/bitstream/tede/5886/1/459184.pdf. Acesso em 05 de dezembro de 2018.

TAVARES, Oswaldo Hamiltop. A influência do Código Canônico no Código Civil Brasileiro.

Disponivel

em

http://midia.apmp.com.br/arquivos/pdf/artigos/2015_influencia_direito_canonico_ccb. pdf. Acesso em 10 de dezembro de 2018.

TUCCI, José Rogério Cruz e AZEVEDO, Luiz Carlos de, Lições de Processo Civil Canônico, Edit. Revista dos Tribunais, S.Paulo, 2001, pp. 241

VIEIRA, Leonardo Alves. Hegel e a História Mundial. Revista Veritas, Porto Alegre, v. 51, n. 1, p. 69-83, mar. 2006. Disponível em <https://goo.gl/QGRMj6>. Acesso em 18 de dezembro de 2018.

VIEIRA, Tarcisio Pedro. Revista de Direito Canônico. Disponível em https://www.infosbc.org.br/site/noticias/3668-instituto-superior-de-direito-canonicosanta-catarina-isdcsc. Acesso em 10 de dezembro de 2018.

https://oglobo.globo.com/sociedade/religiao/papa-facilita-processo-para-quecatolicos-se-casem-pela-segunda-vez-na-igreja-17427659. Acesso em 12 de dezembro de 2018. 
https://elpais.com/elpais/2018/03/12/album/1520854925_297953.htm|\#foto_gal_26. Acesso em 12 de dezembro de 2018.

Enviado: Abril, 2019.

Aprovado: Junho, 2019. 